\title{
Penggunaan Aplikasi eVoting Berbasis Decision Support Systems pada Pilkades (Studi Kasus : DesaKedungbanjar, Taman, Pemalang)
}

\author{
Andi Rosano \\ Fakultas Teknik \\ Universitas Bina Sarana Informatika \\ J1. Kamal Raya no. 18, Jakarta, Indonesia \\ andi.aox@bsi.ac.id \\ Nur Ali Farabi \\ Fakultas Teknologi Informasi \\ Universitas Bina Sarana Informatika \\ J1. Kamal Raya no. 18, Jakarta, Indonesia \\ nur.naf@bsi.ac.id
}

\begin{abstract}
Tujuan penelitian ini adalah mendukung proses demokrasi di Indonesia dengan memanfaatkan teknologi informasi pada pemilihan kepala daerah/desa (pilkada/pilkades) dengan menggunakan aplikasi eVoting berbasis Decision Support Systems (DSS). Proses eVoting dipakai agar proses bisa berlangsung dengan cepat, akurat, dan efisien. Sedangkan aplikasi DSS digunakan untuk membantu pemilih dalam menentukan pilihannya tepat sesuai dengan keinginannya. Tujuan khusus yang ingin dicapai adalah membuat aplikasi eVoting berbasis DSS untuk diimplementasikan pada pemilihan kepala daerah/desa melalui kajian teoritis dan analisis kebutuhan. Metoda penelitian yang dilakukan adalah metode survey dalam pengambilan data, seperti wawancara dan kuesioner guna medapatkan data primer. Sedangkan data sekunder diperoleh dari situs resmi Pemerintah Daerah, yang pada penelitian ini dilakukan di Kabupaten Pemalang. Metoda analisis seperti Strength Weakness Opportunity Threats (SWOT) dan Critical Success Factor (CSF) dilakukan untuk mendukung perancangan aplikasi eVoting. Model Analitical Hierarchy Process (AHP) dan Database Relational digunakan pada perancangan aplikasi DSS. Hasil penelitian ini dalam bentuk rancangan aplikasi eVoting berbasis DSS, yaitu rancangan model, database, dan user interface. Pemanfaatan aplikasi eVoting berbasis DSS diharapkan mampu meningkatkan efektivitas dan efisiensi proses demokrasi dan dapat dimanfaatkan sebagai model aplikasi bagi pemilihan kepala daerah/desa lainnya di Indonesia.
\end{abstract}

Kata Kunci; eVoting, Database, Pilkades, Decision Support Syste

I. PENDAhUluan

Pada bulan Maret 2010 yang lalu Mahkamah Konstitusi telah memutuskan bahwa pemilu dengan metode electronic voting diperbolehkan, sesuai dengan putusan hasil sidang uji materi pasal 88 Undang-undang nomor 32 tahun 2004, atas dasar asas manfaat agar pasal tersebut memiliki dasar konstitusional. Berdasarkan keputusan MK tersebut maka seluruh daerah di Indonesia sudah 
diperbolehkan mengadakan Pemilihan Kepala Desa (Pilkades) dengan menggunakan metode $e$ Voting atau Electronic Voting (http://www.mahkamahkonstitusi.go.id,2010).

Di seluruh dunia sudah ada 17 negara yang menggunakan eVoting, diantaranya adalah negara maju seperti Amerika, Rusia, dan Jepang dengan hasil memuaskan. Kemudian ada 18 negara lain yang sudah menguji coba eVoting antara lain Meksiko, Chile, Argentina dan berbagai negaraAfrika seperti Afrika Selatan dan Nigeria. Untuk di kawasan Asean Philipina adalah pionir, dimana pada pemilu parlemen maupun presiden beberapa tahun lalu telah menggunakan eVoting dan sukses menjadikan Aquino III sebagai presiden dengan cara yang jujur dan adil. Pemilu Philipina dengan jumlah pemilih sebesar 38 juta pemilih, hasilnya dapat diketahui langsung dalam waktu sehari. Sedangkan India dengan jumlah pemilih lebih dari 1 milyar jiwa juga berhasil melaksanakan $e$ Voting secara cukup efisien. Anggaran yang dipakai adalah 0.75 dollar US tiap jiwa. Analogi dengan India, Indonesia dengan penduduk sekitar 200 juta pemilih maka hanya memerlukan 150 juta dollar atau sekitar 1.5 triliun rupiah, atau 7\% dari Anggaran Pemilu 2009 saat itu yang mencapai 21 triliun rupiah. Pemakaian teknologi layar sentuh telah diterapkan juga di Belgia, Brazil, Estonia, France, Germany, India, Ireland, Netherland, UK, USA, Switzerland (Allers Maarten \& Kooreman Peter, 2009).

Sedangkan di Indonesia sendiri, pemilihan kepala desa secara elektonis telah beberapa kali diterapkan, antara lain di Kabupaten Jembrana Bali pada pemilihan kepala dusun (Pilkadus) sejakJuli 2009 dimana terdapat 54 dusun yang melakukan pilkada secara eVoting di kabupaten tersebut. Pemungutan suara secara elektonis itu terutama bertujuan untuk menekan biaya penyelenggaraan pilkada. Bila dihitung biayapelaksanaan pilkada dengan eVoting bisa menghemat lebih dari 60 persen dibandingkan pilkada konvensional dengan surat suara.

\section{Tinjauan Pustaka}

Penerapan eVoting dalam proses demokrasi yang telah dilakukan penelitiannya, membuktikan bahwa eVoting dapat meningkatkan partisipasi pemilih (Carter and Belangers, 2005), melakukan penelitian tentang model eGovernment dalamaplikasi sistem voting secara online. Beberapa penelitian lainnya adalah : Collins and Butler (2002); GAO (2004); West (2004); dan McMillen (2004).

\section{Voting}

Voting atau pemungutan suara sudah menjadi salah satu metode pengambilan keputusan penting dalam kehidupan manusia zaman sekarang. Voting digunakan mulai dari tingkat masyarakat terkecil, yaitu keluarga, organisasi, sampai dengan tingkat negara. Voting berfungsi untuk mengumpulkan aspirasi dari seluruh elemen masyarakat, untuk kemudian menemukan jalan keluar terbaik untuk menyelesaikan permasalahan yang ada. Pada negara yang memakai sistim politik demokrasi, voting digunakan untuk mengambil keputusan negara yang sangat penting, antara lain untuk menentukan wakil-wakil rakyat, atau memilih pemimpin negara yang baru. Kemajuan teknologi informasi saat inilah yang membawa perubahan yang besar tersebut,salah satunya adalah metode voting ini. Pemakaian teknologi komputer untuk pelaksanaan voting ini dikenal sebagai electronic voting atau biasa disebut dengan eVoting. (Azhari.R, 2005).

Pengertian dari eVoting secara umum adalah pemakaian teknologi komputer pada pelaksanaan voting. Sedangkan pilihan teknologi yang dipakai untuk implementasi dari eVoting sangat bervariasi, antara lain pemakaian smart card untuk otentikasi pemilih, pemakaian internet untuk sistem pemungutan suara, pemakaian touch screen atau layar sentuh sebagai ganti dari kartu suara, dan masih banyak ragam teknologi yang digunakan(Schaupp, 2005). 
Di benua Eropa dan Amerika, penerapan eVoting telah berjalan dengan baik di beberapa negara. Tiap negara menerapkan sistem eVoting tersendiri yang tentunya disesuaikan dengan kondisi dan infrastruktur yang telah ada di negara tersebut. Contoh, negeri Belanda mempunyaisistem eVoting yang disebut RIES (RijnlandInternet Election System). Sistem ini berbasis internet sebagai media pemungutan suara.

MagiTriinu (2007) dalam tesisnya menyatakan bahwa secara umum eVoting terdiri dari enam tahapan (phase) seperti terlihat padagambar 1.

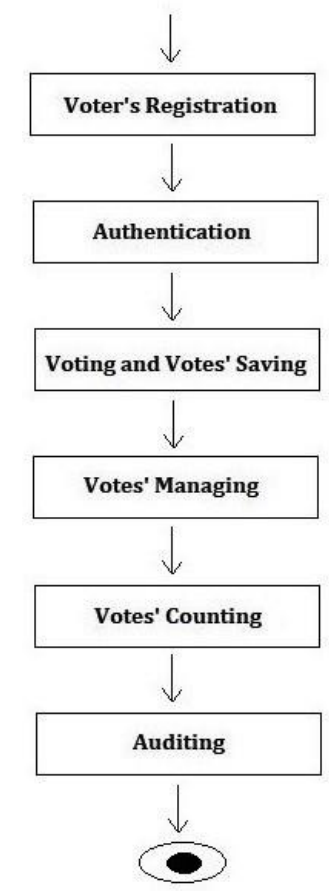

Gambar 1. Tahapan eVoting (MagiTriinu, 2007)

\section{Decision Support System (DSS)}

Aplikasi DSS terdiri dari beberapa subsistem yaitu : subsistem manajemen data, subsistem manajemen model, dan subsistem manajemen interface (Turban, 2007). DSS dapat memecahkan masalah terstruktur dengan aplikasi pola pemecahan masalah human-machine. Sedangkan bagian yang tidak terstruktur ditentukan oleh si pengambil keputusan (Shim, Warkentin et al, 2002).

DSS mempunyai dua ciri atau klasifikasi utama yang dilihat dari struktur masalah dan tingkat pengambilan keputusan (Turban, 2007). Struktur masalah dibedakan menjadi 'terstruktur' yaitu kegiatan yang memerlukan pemecahan secara rutin atau berulang Kedua masalah 'tidak terstruktur' yaitu masalah-masalah yang kompleks dan memerlukan keputusan yang cepat/segera. Sedangkan masalah 'semi-terstruktur' adalahmasalah yang memerlukan hanya sebagian tahapan dari pengambilan keputusan. Adapun tingkat pengambilan keputusan terdiri dari strategic planning, management control, operational control. Penggunaan DSS terutama adalah untuk masalah semi-tersetruktur yaitu padatingkat management control.

Analytical Hierarcy Process (AHP)

Metode Analytical Hierarcy Process (AHP) dikembangkan oleh Thomas L. Saaty pada tahun 70-an ketika di Watson School (Saaty, 2008). Metode AHP adalah salah satu metode yang dapat dipakai dalam sistem pengambilan keputusan dengan faktor-faktornya yaitu : persepsi, preferensi, pengalaman 
dan intuisi. $A H P$ merupakan gabungan dari penilaian-penilaian dan nilai-nilai pribadi ke dalam satu cara yang logis.

Analytical Hierarcy Process (AHP) dipakai untuk menyelesaikan permasalahan multikriteria yang kompleks dan merupakan suatu hierarki. Masalah yang kompleks dimaksudkan terdiri dari masalahmasalah yang begitu banyak(multikriteria), struktur masalah yang belum jelas, ketidakpastian pendapat dari pengambil keputusan, pengambil keputusan terdiri dari beberapa orang, serta tidak akuratnya data yang tersedia. Menurut Saaty, hierarki didefinisikan sebagai suatu representasi dari sebuah permasalahan yang kompleks dalam suatu strukturmulti level dimana level pertama adalah tujuan, yang diikuti level faktor, kriteria, subkriteria, dan seterusnya ke bawah hingga level terakhir darialternatif. Dengan konsep ini suatu masalah yang kompleks dapat diuraikan menjadi kelompok- kelompok yang kemudian disusun menjadi bentuk hierarki sehingga permasalahan tampak lebih terstruktur dan sistematis.

Metode ini merupakan sebuah kerangka pengambilan keputusan yang efektif atas persoalan dengan menyederhanakan dan mempersingkat proses pengambilan keputusandengan cara memecahkan persoalam tersebutkedalam bagian-bagiannya, menyusun variabel

dalam suatu susunan hierarki, memberikan nilai numerik pada pertimbangan subyektif tentang pentingnya tiap variabel dan mensintesis berbagai pertimbangan yang bertujuan untuk menetapkan variabel yang mana yang menjadi prioritas paling tinggi dan melakukan sesuatu untuk mempengaruhi hasil pada kondisi tersebut.Metode ini menggabungkan kekuatan dari perasaan manusia dan logika yang berkaitandengan berbagai persoalan, lalu menggabungkan berbagai pertimbangan beragam menjadi hasil yang sesuai dan cocok dengan perkiraan sebelumnya yang intuitif, sebagaimana yang ditunjukkan pada pertimbangan yang telah dibuat sebelumnya.

AHP mempunyai landasan pemikiran aksiomatik yang terdiri dari :

a. Reciprocal Comparison, yang mengandung arti bahwa pengambil keputusan harus bisa membuat perbandingan dan menyatakan preferensinya. Preferensinya tersebut harus memenuhi 'syarat resiprokal', yaitu Bila A lebih disukai dari B dengan skala x, maka B lebih disukai dari A dengan skala y.

b. Homogenity, yang mengandung arti preferensi seseorang harus dapat dinyatakan dengan skala terbatas atau unsur-unsurnya dapat dibandingkan satu sama lain.

c. Independence, yang berarti preferensi dinyatakan dengan asumsi bahwa kriteria tidak terpengaruh oleh alternatif-alternatif yang ada tetapi oleh obyektivitas secarakeseluruhan.

d. Expectation, artinya untuk tujuan pengambilan keputusan, struktur hierarkidiasumsikan lengkap. Apabila asumsi ini tidak dipenuhi maka pengambilan keputusan tidak memakai seluruh kriteria dan atau obyektif yang tersedia (diperlukan) sehingga keputusan yang diambil dianggap tidak lengkap.

Tahapan pengambilan keputusan dalam metodeAHP pada dasarnya adalah sebagai berikut :

a. Mendefinisikan masalah dan menentukan solusi yang diinginkan

b. Membuat struktur hierarki yang diawali dengan tujuan umum, dilanjutkan dengan kriteria-kriteria dan alternatif-alternatifpilihan yang ingin dirangking.

c. Membentuk matriks perbandingan berpasangan yang menggambarkan kontribusi relatif atau pengaruh setiap unsur terhadap masingmasing tujuan atau kriteria yang setingkat diatas. Perbandingan dilakukan berdasarkanpilihan atau 
judgement dari pembuat keputusan dengan menilai tingkat-tingkat kepentingan suatu unsur dibandingkan unsur lainnya.

d. Menormalkan data yaitu dengan membagi nilai dari setiap unsur di dalam matriksyang berpasangan dengan nilai total dari setiap kolom.

e. Menghitung nilai eigen vector dan menguji konsistensinya, jika tidak konsisten maka pengambilan data (preferensi) perludiulangi. Nilai eigen vector yang dimaksudadalah nilai eigen vector maksimum

f. Mengulangi langkah 3, 4, dan 5 untuk seluruh tingkat hierarki

g. Menghitung eigen vector dari setiap matirks perbandingan berpasangan. Nilai eigen vector merupakan bobot setiap unsur. Langkah ini untuk menggabungkan pilihan dalam penentuan prioritas unsur pada tingkat hierarki terendah sampai pencapaian tujuan

h. Menguji konsistensi hierarki. Jika tidak memenuhi kriteria $C R<0,100$ makapenilaian harus diulangi kembali.

AHP telah berhasil diterapkan untuk memecahkan masalah pemilihan proyek dalam sistem informasi (Chen and Huang, 2004), aplikasi manajemen sumber daya manusia (Trisnawarman, 2005). AHP juga telah berhasilditerapkan untuk memecahkan banyak masalah dan telah dipublikasikan di 1000 artikel lebih dalam sepuluh tahun terakhir (Forman and Gass, 2001).

Analisa SWOT dan CSF-KPI eVoting DesaKedungbanjar Pemalang

Analisa SWOTStrength:

- Pemimpin yang visioner

- Sumber daya alam yang berlimpah

- Anggaran yang memadai

Weakness :

- Sumber daya manusia yang tidak terlatih

- Kesadaran budaya terhadap teknologiinformasi (TI) yang belum memadai

- Tingkat Pendidikan yang tidak merata

- Infrastruktur TI yang kurang memadai

Opportunity :

- Penerapan eKTP

- Perencanaan pembangunan infrastrukturTI

- Perkembangunan pembangunan daerah yang pesat

\section{Threats :}

- Kecurigaan masyarakat

- Politik uang

- Keamanan TI 
Analisa CSF-KPI seperti yang ditunjukkan pada tabel 1

Tabel 1. Analisa CSF-KPI

\begin{tabular}{|c|c|}
\hline $\begin{array}{c}\text { Critical Success } \\
\text { Factor (CSF) }\end{array}$ & $\begin{array}{c}\text { Key Performance } \\
\text { Indicator }\end{array}$ \\
\hline $\begin{array}{c}\text { Ketersediaan IT } \\
\text { yang memadai }\end{array}$ & $\begin{array}{c}\text { Tersedianga komputer dan } \\
\text { perlengkapannya di area } \\
\text { pemilihan }\end{array}$ \\
\hline $\begin{array}{c}\text { Kepemimpinan } \\
\text { yang visioner }\end{array}$ & $\begin{array}{c}\text { Mendukung pelaksanaan } \\
\text { eVoting dan Mengawasi } \\
\text { implementasi eVoting }\end{array}$ \\
\hline $\begin{array}{c}\text { Anggaran yang } \\
\text { mencukupi }\end{array}$ & $\begin{array}{c}\text { Tersedianya dana untuk } \\
\text { pelaksanaan eVoting }\end{array}$ \\
\hline $\begin{array}{c}\text { Adanya } \\
\text { manajemen } \\
\text { perubahan }\end{array}$ & $\begin{array}{c}\text { masyarakat terhadap } \\
\text { pelaksanaan eVoting dan } \\
\text { bersedianya masyarakat } \\
\text { menjalankan eVoting }\end{array}$ \\
\hline
\end{tabular}

II. TeKNIK Pengumpulan Data Pengambilan data primer dilakukan di Desa Kedungbanjar Kabupaten Pemalang secaralangsung pada bulan November 2018. Objek penelitian adalah Kabupaten Pemalang yaitu pemilihan Kepala Desa Kedungbanjar .

\section{A. Metode Penelitian}

Metode penelitian yang diterapkan dalam pengambilan data adalah metode Fact Finding Technique (FFT) (Connoly, 2005) yaitu : wawancara, kuesioner dan observasi untuk mendapatkan data primer, sedangkan pemeriksaan dokumen dan riset digunakan untuk mendapatkan data sekunder, seperti website resmi Pemerintahan

Kabupaten, Rencana Pembangunan JangkaMenengah Daerah (RPJMD) dan Laporan Penyelenggaraan Pemerintahan Daerah (LPPD).

Kemudian dilakukan analisis data yang berhasil dikumpulkan, metode analisis yang digunakan adalah analisis Strength Weakness Opportunity Threats (SWOT), analisis Critical Success Factor (CSF) dan Key Performance Indicator (KPI) pada tahap perancangan database relasional dan model Analitical Hierarchy Process $(A H P)$ serta perancangn user interface. Hasil penelitian ini berupa hasil analisis kebutuhan dalam pemilihan kepala desa dan rancangan aplikasi eVoting dengan model pengambilan keputusan untuk pemilihan kepaladesa.

\section{B. Hasil dan Pembahasan}

Kuesioner yang disebar secara acak, sejumlah sebanyak 150 kuesioner, dan yang berhasil dikembalikan (dapat didata) sekitar 123 responden.

Analisis Data Kuesioner

1. Data Usia Responden menunjukkan bahwausia responden kurang dari 20 tahun adalah 13\%, 21-30 
tahun 18\%, 31-40 tahun 22\%, 41-50 tahun 33\% dan diatas 50 tahun 14\%Data Jenis Kelamin, jumlah responden

laki-laki adalah $67 \%$ dan wanita $33 \%$

2. Data Pekerjaan, jumlah responden dengan pekerjaan sebagai petani adalah $63 \%$, pegawai negeri $3 \%$, wiraswasta $16 \%$, karyawan swasta $2 \%$, dan pekerjaan lainnya $16 \%$

3. Data Tingkat Pendidikan, responden dengan Pendidikan sebagai sarjana 1\%, SMA 14\%, SMP 37\%, SD 41\%, tidak tamat SD/tidak sekolah 7\%

4. Data Penghasilan, responden yang memiliki penghasilan kurang dari 1 juta adalah $14 \%, 1-2$ juta $64 \%, 2,1-4$ juta $3 \%$, lebih dari 4 juta $7 \%$.

5. Data Jumlah anggota keluarga dalam satu rumah, jumlah anggota keluarga respondendalam satu kurang dari 2 orang 0\%, 2-4 orang $11 \%, 5-7$ orang $66 \%, 8-10$ orang $16 \%$, dan lebih dari 10 orang $7 \%$

6. Data Status, responden dengan status kawin berjumlah $69 \%$, tidak kawin $20 \%$, dan janda/duda $1 \%$

7. Data Domisili, responden yang berdomisili di pusat desa berjumlah $41 \%$, pinggir desa $47 \%$, jauh dari pusat desa $12 \%$

Analisis Pertanyaan Kuesioner eVoting PemilihanKepala Desa

1. Sikap responden terhadap pemilihan kepala desa; $68 \%$ mendukung, $18 \%$ menjawab tidak tahu, $14 \%$ tidak mendukung

2. Kepercayaan terhadap proses sistem pemilihan saat ini; $48 \%$ menjawab percaya, $41 \%$ tidak tahu, dan $11 \%$ tidak percaya

3. Minat responden untuk mengikuti proses pemilihan kepala desa; $59 \%$ menjawab berminat, $16 \%$ menjawab tidak tahu, dan $25 \%$ menjawab tidak berminat

4. Kriteria usia sebagai pertimbangan pemilih dalam pemilihan calon kepala desa; $64 \%$ responden menjawab setuju, $28 \%$ tidak tahu, dan $8 \%$ menjawab tidak setuju

5. Kriteria Pendidikan sebagai pertimbangan pemilih dalam pemilihan calon kepala desa; $78 \%$ menjawab setuju, $18 \%$ tidak tahu, dan $4 \%$ menjawab tidak setuju

6. Kriteria program kerja atau visi-misi sebagai pertimbangan pemilih dalam pemilihan calon kepala desa; $86 \%$ menjawab setuju, $12 \%$ tidak tahu, dan $2 \%$ menjawab tidak setuju

7. Kriteia pengalaman organisasi atau kepemimpinan sebagai pertimbangan pemilih dalam memilih calon kepala desa; $41 \%$ responden menjawab setuju, $45 \%$ tidak tahu, dan $14 \%$ tidak setuju

8. Kriteria kejujuran/tidak pernah korupsi sebagai pertimbangan pemilih dalam memilih calon kepala desa; $78 \%$ menjawab setuju, $22 \%$ menjawab tidak tahu, dan $0 \%$ menjawab tidak setuju

9. Kriteria kekayaan sebagai pertimbangan pemilih dalam memilih calon kepala desa; $63 \%$ responden menjawab setuju, $27 \%$ tidak tahu, dan $10 \%$ menjawab tidak setuju

10. Kriteria asal daerah sebagai pertimbangan 
pemilih dalam memilih calon kepala desa; $46 \%$ menjawab setuju, 3\% tidak tahu, dan 51\% menjawab tidak setuju

11. Pengetahuan tentang eVoting; $45 \%$

responden menjawab tidak tahu, 52\% tidakmenjawab, $3 \%$ menjawab tahu

12. Pengenalan tentang komputer; $7 \%$

responden menjawb mengenal, 34\% tidak menjawab, dan 59\% menjawab tidak mengenal

13. Penggunaan komputer; $78 \%$ responden menjawab tidak pernah, $16 \%$ tidakmenjawab, dan $6 \%$ menjawab pernah

14. Tingkat kepercayaan terhadap proses pemilihan kepala desa menggunakan komputer; $82 \%$ responden menjawab tidak tahu, $8 \%$ tidak percaya dan $10 \%$ menjawabpercaya

\section{PENGAMBILAN KEPUTUSAN}

Dari Analisa data kuesioner diatas maka dapatdiambil beberapa kriteria yang menjadi pertimbangan dalam menentukan pilihan kepala desa. Kriteria tersebut adalah : usia, pendidikan, pengalaman kepemimpinan program kerja, dan visi-misi. Berdasarkan kriteria tersebut maka dibuatlah model $A H P$ untuk pengambilan keputusan.

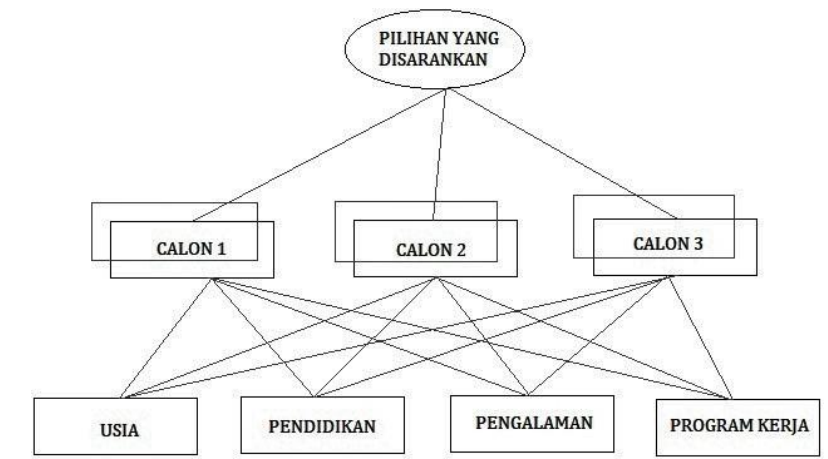

Gambar 2. Model AHP eVoting PilkadesRancangan Database

Rancangan menggunakan model relasional database yaitu hubungan antar tabel yang dapat diimplementasikan menggunakan perangkat lunak database management system (DBMS) seperti MySQL, Microsoft SQL Server, dsb. Berikutadalah rancangan database eVoting.

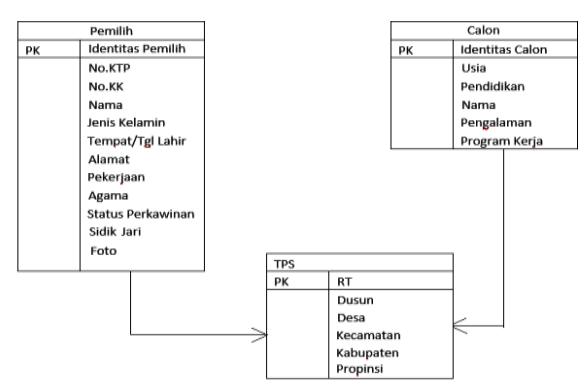

Gambar 3. Entity Relationship Diagram

Rancangan sistem Pendataan Pemilih

Pendataan pemilih dilakukan diawal proseseVoting, dimana setiap penduduk desa harus didaftarkan pada sistem berbasis pada Kartu Keluarga (KK) dan Kartu Tanda Penduduk (KTP). Penduduk yang 
didaftarkan pada sistem oleh petugas harus mendatangi (diundang) ke Kantor Kepala Desa untuk keperluan pemotretan dan perekaman sidik jari/jempol. Tidak boleh ada satu pun penduduk yang berhak dan memiliki suaraterlewatkan datanya. Sidik jari yang direkam merupakan password untuk sistem pilkada ini, sedangkan User_Id adalah Nomor IndukKependudukan yang tertera pada KTP.

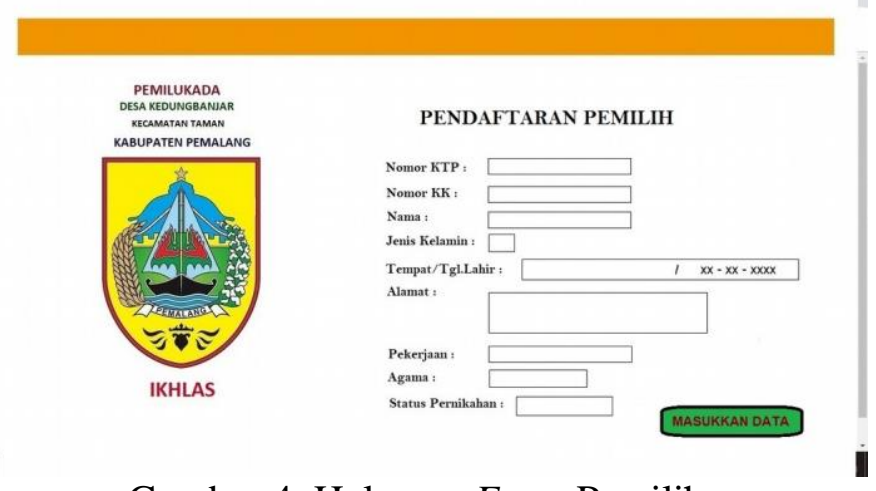

Gambar 4. Halaman Entry Pemilih

Setiap peng-inpu-tan data pemilih diikutidengan pemotretan wajah dan scan sidik jari, setelah petugas yakin bahwa data yang diinput sudah benar dengan konfirmasi pemilih. Jika data sudah benar petugas mengklik tombol 'BENAR' lalu muncul kembali layar peng-inpu-tan. Jika data belum benar atau perlu diulang, petugas mengklik tombol 'ULANGI' dan layar kembali kepeng-input-an data pemilih.
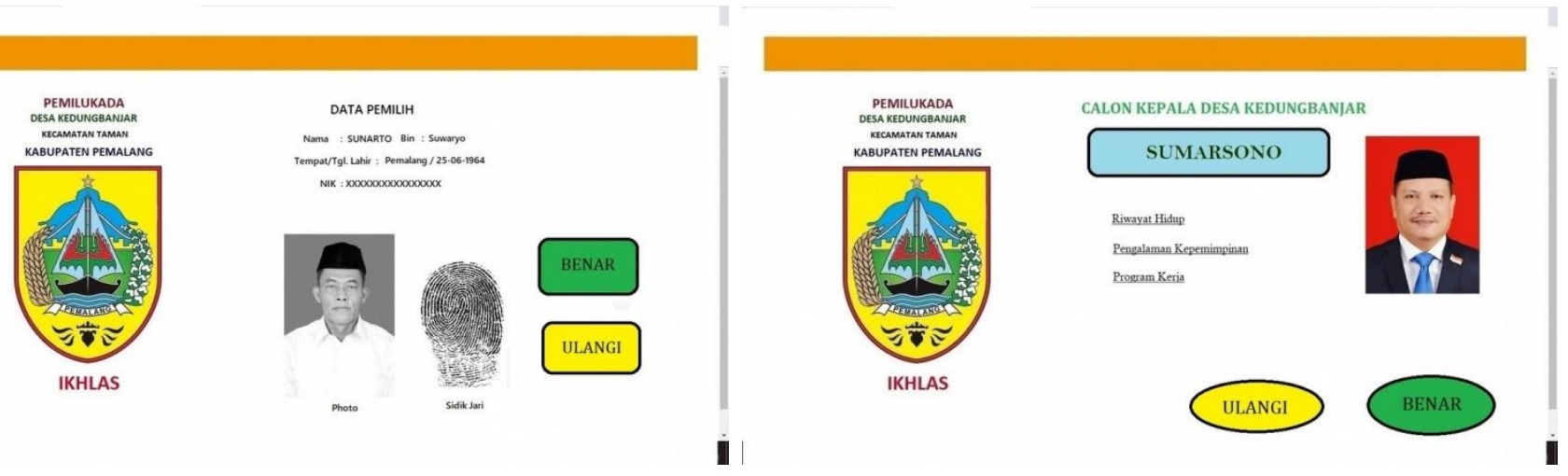

Gambar 5. Konfirmasi Data Pemilih

Rancangan sistem Pendaftaran Calon Kepala DesaPendaftaran calon kepala desa dilakukan oleh petugas Kantor Kepala Desa dengan datakependudukan ditambah dengan Riwayat Hidup, Pengalaman Kepemimpinan, dan Program Kerjayang akan dilaksanakan.

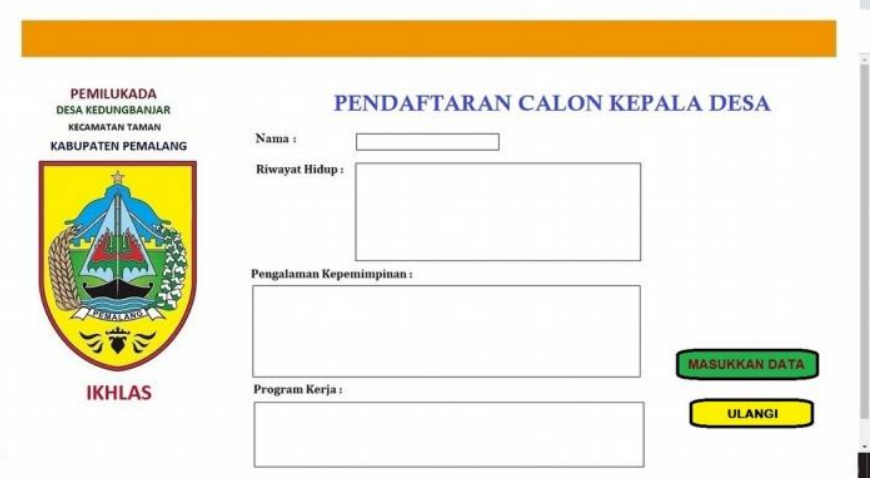

This is an Creative Commons License This work is licensed under a Creative Commons AttributionNonCommercial 4.0 International License. 
Gambar 6. Halaman Entry Calon Kades Setelah dilakukan peng-inpu-tan calon kepala desa, muncul halaman konfirmasi Calon Kepala Desa. Bila data telah benar petugas mengklik tombol 'BENAR' dan halaman berpindah ke peng-inpu-tan lagi. Bila masih ada yang salah petugas mengklik tombol 'ULANGI'.

\section{Gambar 7. Konfirmasi Calon Kades}

Rancangan User Interactive Pelaksanaan eVoting Pemilih melaksanakan pemilihan calon Kades diawali dengan validasi data Nomor Induk Kependudukan atau Nomor KTP, dan scan sidik jari/jempol. Sehingga pemilih tidak bisa diwakili orang lain, harus dirinya sendiri yang melakukan eVoting. Setelah data pemilih valid maka halaman berikutnya akan muncul daftar calon kepala desa yang terdaftar, selanjutnya pemilih melakukan pemilihan dengan menyentuh gambar/photo dari calon yang menjadi pilihannya dan layar berubah ke halaman konfirmasi. Jika sudah yakin calon yang dipilih maka menekan tombol 'PILIH', namun jika masih ragu-ragu dapat menyentuh tombol 'ULANGI'. Interface/rancangan layar Web Aplikasi eVoting dapat dilihat pada gambar berikut ini.

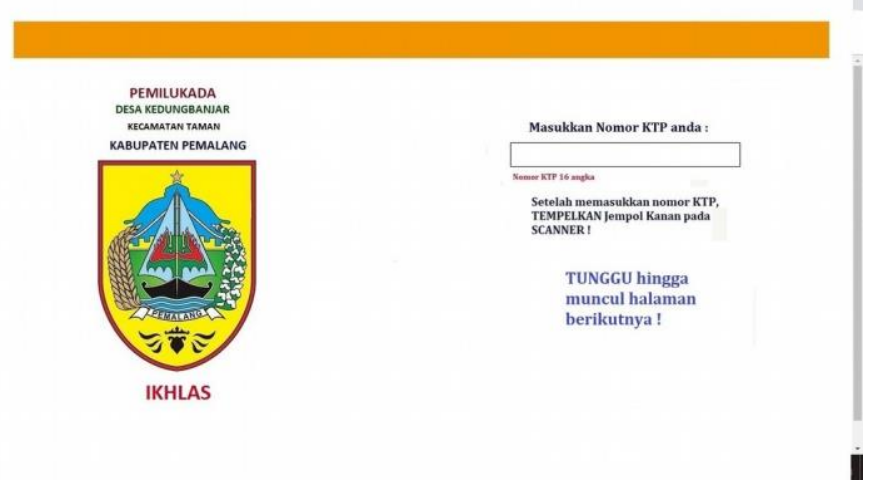

\section{Gambar 8. Halaman Login Pemilih}

Setelah beberapa detik kemudian akan muncul halaman perintah untuk pemilih agar menempelkan jempol tangan kanan pada mesin scanner. Bila data pemilih sudah didaftarkan pada sistem, maka data pemilih akan muncul di layar berikutnya.

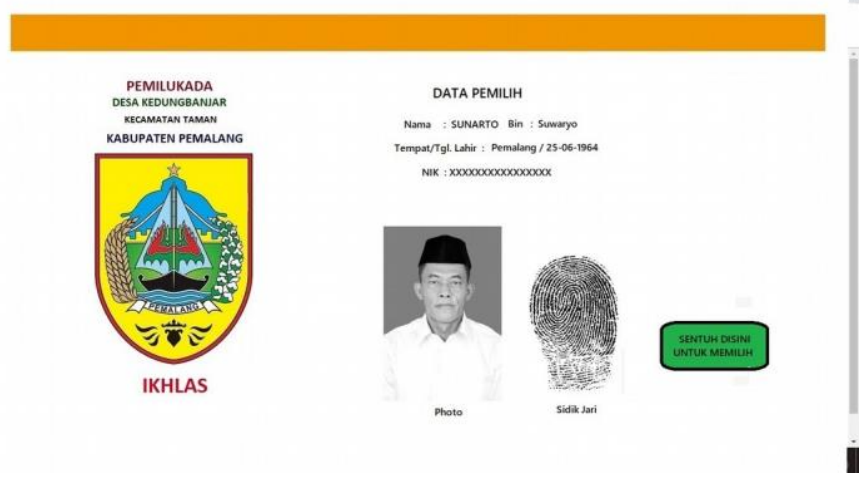

Gambar 9. Data Pemilih Benar Kemudian setelah pemilih menyentuh tombol 'Sentuh disini untuk memilih', maka layarkemudian yang muncul adalah : 
Gambar 9. Data Pemilih Benar Kemudian setelah pemilih menyentuh tombol 'Sentuh disini untuk memilih', maka layarkemudian yang muncul adalah :

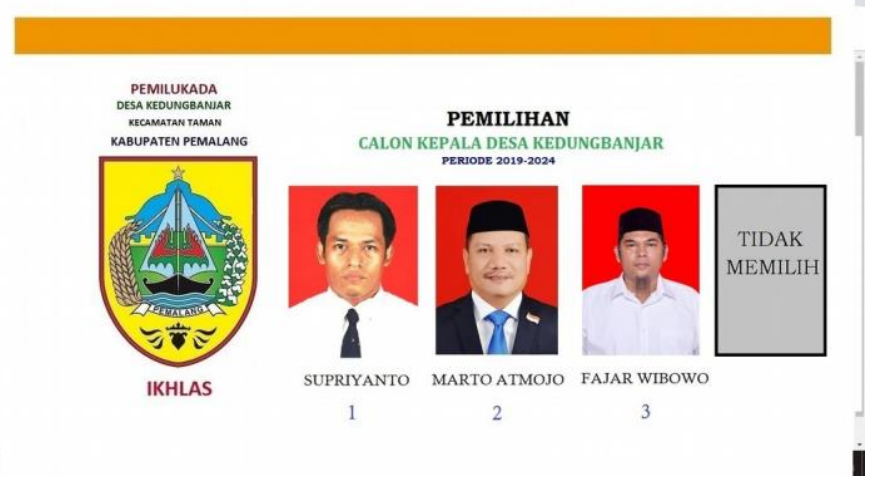

Gambar 10. Halaman Calon Kepala Desa

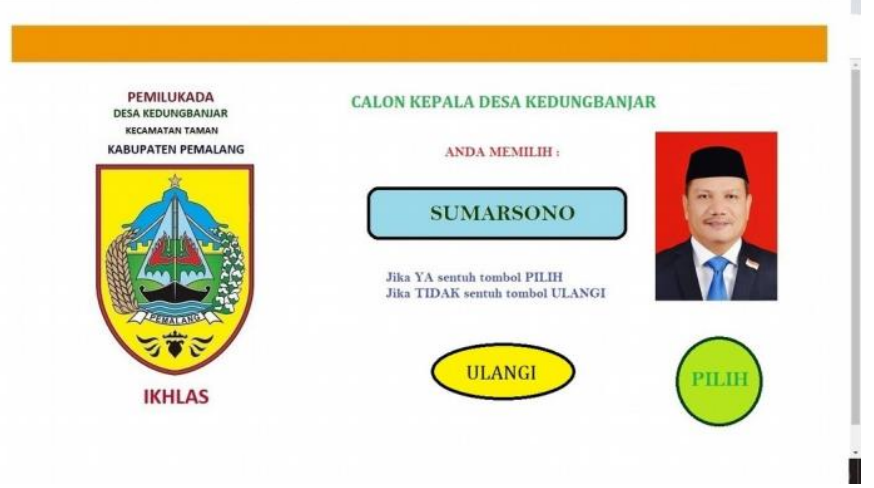

Gambar 11. Halaman Konfirmasi Calon dipilihBila pemilih selesai melaksanakan pemilihan akan muncul halaman 'TERIMA KASIH' dan dalam satu menit layar kembali ke halaman loginpemilih.

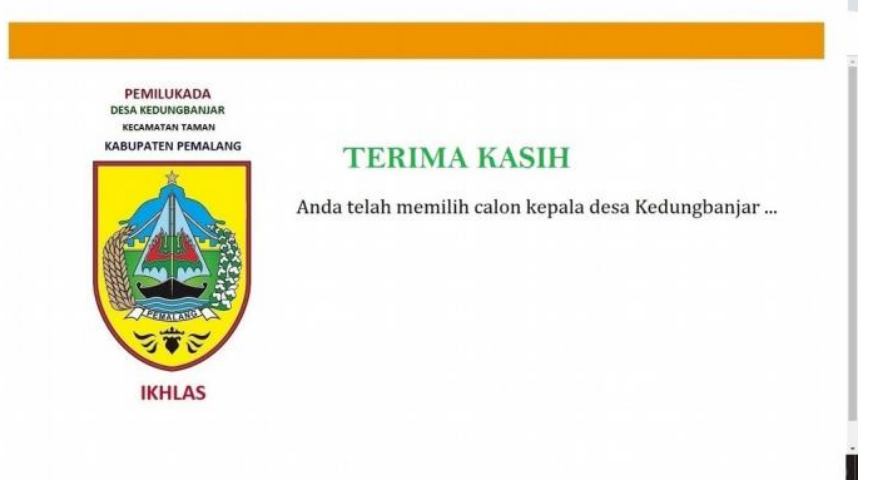

Gambar 12. Informasi Selesai MemilihRekapitulasi Hasil eVoting

Pada akhir masa pelaksanaan voting, maka panitia yang memiliki kewenangan untuk melakukan proses penghitungan suaramelakukan eksekusi menu rekapitulasi suara.Sistem kemudian akan membuat laporan rekap suara, baik seluruh perolehan suara calon kades yang ada. Dari laporan rekapitulasi suara tersebut kemudian diumumkan dan dicetak, untuk kemudia dilakukan rapat penentuan pemenang pemilihan kades yang telah dilakukan. 


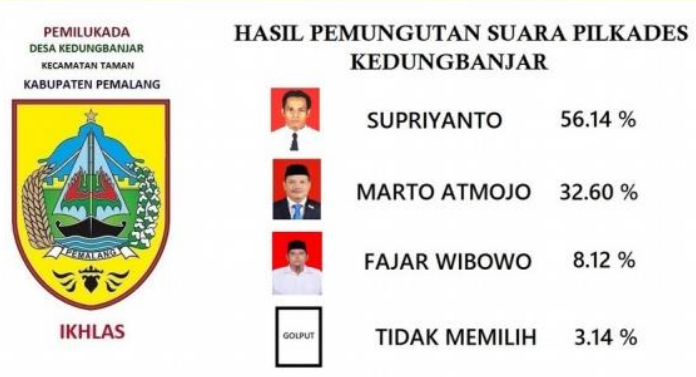

Gambar 13. Hasil eVoting

\section{KESIMPULAN}

Dari hasil penelitian dapat disimpulkansebagaI berikut :

1. Penduduk desa di Kabupaten Kedungbanjar Pemalang sebagian besarmendukung proses pemilihan kepala desa dengan cara baru, walaupun sebenarnya belum mengenal proses eVoting.

2. Adanya dukungan dari pemerintah Kabupaten Pemalang untuk melaksanakan eVoting sangat diperlukan.

3. Dalam pemilihan kepala desa, pendidikan, pengalaman, usia, program kerja, dan visi- misi menjadi faktor penting untuk pertimbangan pemilih.

4. eVoting dapat diterapkan dalam proses pemilihan kepala desa di DesaKedungbanjar Kabupaten Pemalang dengan baik.

5. Rancangan sistem eVoting yang telah dibuat dapat mempercepat prosespemilihan, menghemat biaya dan memperkecil peluang kecurangan.

\section{SARAN}

Dalam penerapan eVoting yang pertama kali makaperlu diperhatikan hal-hal berikut :

1. Perlu dilakukan penyuluhan tentang rencana (proyek) eVoting sebelum pelaksanaan pilkades agar pemilih mendapat pengetahuan yang cukup.

2. Sosialisasi tahapan pelaksanaan eVoting yang cukup agar penduduk desa yakin dengan metode pemilihan tersebut

3. Perlu uji coba eVoting (simulasi) sebelum pelaksanaan eVoting yang sesungguhnya

\section{REFERENSI}

Allers Maarten, A. \& Kooreman, Peter. (2009). More Evidence of the effect of voting technology on election outcomes. Public Choice 139; 159-179

Azhari, Rakhmad, (2005). E-Voting, Jurnal SistemInformasi MTI-UI vo. 1 no. 1 (Sep. 2005)

Carter, L.. and Belanger, F. (2005), TheUtilizationof e-government services, citizen trust innovation and acceptance factors.Information

Systems Journal, Vol.15, No.1, pp. 5-25

Chen, C.J. and Huang, C.C. (2004). A Multiple criteria evaluation of high-tech industries for the science 
based industrial park in Taiwan. Information and Management, Vol 41,No. 7, pp.839-851

Conolly, Thomas and Berg, Carolyn. (2005). Database Systems : A Practical Approach In Design, Implementationand Management $4{ }^{\text {th }}$ Edition. Harlow : Addition Wesley

Collins, N. and Butler, P. (2002). The marketplace,e-government and e-democrazy, Iris

Marketing Review, Vol.15 No.2, pp.86-93

Forman, E.H. and Gass, S.J. (2001). The Analityc Hierarchy Process - An Exposition Operation Research Vol. 49, No. 4, pp.469-486

GAO, General Accounting Office, (2004),Electronic voting offers opportunitiesand presents challenges, 20 july 2004, available at www.gao.gov/new.items/d04975t.pdf

Magi Triinu, (2007), Practical Security Analysis of E-voting Systems. Tesis TALLIN UNIVERSITY OF TECHNOLOGY

Faculty of Information Technology Deoartment of Informatics Chair of Information Security

McMillen, D. (2004), Privacy, confidentiality, and data sharing : issues and distinctions. Government Information Quarterly, Vol.21 No. 3, pp. 359-82

Saaty Thomas, L. (2008). Int. J. Services Sciences, Vol. 1, No. 1, 2008 Decision making with the analytic hierarchyprocess

Schaupp L. Christian, Carter Lemuria. (2005). E- voting: from apathy to adoption. Journal of Enterprise Information Management;2005

Trisnawarman, D. (2007). Pengembangan Model Sistem Penunjang Keputusan Manajemen Sumber Daya Manusia.,Proseeding Seminar Nasional Universitas Teknologi Yogyakarta ISBN979-98964-3-6

Shim, J. P., Warkentin, M., at al. Past, present, andfuture of decision support technology, Elsevier, 2002

Turban, Efraim. (2007). Decision Support and Intelligent Systems. Prentice Hall Edition7.

West, D.M. (2004). E-government and the transformation of service delivery and citizen attitudes, public Administration Review, Vol. 64 No. 1 pp. 15-27 